NUNES, M.U.C.; LEAL, M.L.S. Efeitos da aplicação de biofertilizante e outros produtos químicos e biológicos, no controle da broca pequena do fruto e na produção do tomateiro tutorado em duas épocas de cultivo e dois sistemas de irrigação. Horticultura Brasileira, Brasília , v. 19 n. 01 p. $53-59$, março 2.001.

\title{
Efeito da aplicação de biofertilizante e outros produtos químicos e bioló- gicos, no controle da broca pequena do fruto e na produção do tomateiro tutorado em duas épocas de cultivo e dois sistemas de irrigação.
}

\author{
Maria Urbana C. Nunes; Maria Lourdes S. Leal \\ Embrapa Tabuleiros Costeiros, C. Postal 44, 49.001-970 Aracaju - SE. E.mail: murbana@cpatc.embrapa.br
}

\begin{abstract}
RESUMO
Avaliou-se o efeito de biofertilizante, associado ou não a produtos biológicos e químicos, em diferentes condições de irrigação, sobre a produção do tomateiro tutorado e a ocorrência da broca pequena do fruto. Os experimentos foram conduzidos na região de Itabaiana (SE) nos períodos seco e chuvoso. O delineamento experimental foi de blocos ao acaso com 13 tratamentos e quatro repetições, sendo cada parcela composta de 48 plantas no espaçamento de 1,00 x 0,50 $\mathrm{m}$ com uma planta por cova conduzida com duas hastes. A eficiência dos tratamentos variou com a época de plantio e com o sistema de irrigação utilizado. De modo geral, na época chuvosa, obteve-se maiores produções totais e comerciais superando as produções obtidas na época seca em $82 \%$ e $59 \%$, respectivamente, e um maior peso médio de frutos. Também na época chuvosa a percentagem de frutos brocados foi significativamente superior àquela obtida na época seca. Para o plantio na época seca, os melhores tratamentos foram: a) com irrigação por aspersão: Bacillus thuringiensis subsp. Kurstaki (Btk) isolado ou em combinação com clorfluazuron; deltametrina + clorfluazuron e Btk + biofertilizante; b) com irrigação por gotejamento: $B t k+$ clorfluazuron. Para o plantio na época de chuva destacaram-se os tratamentos: a) com irrigação por aspersão: $B t k+$ clorfluazuron; biofertilizante + teflubenzuron e clorfluazuron; b) com irrigação por gotejamento: biofertilizante + clorfluazuron e biofertilizante + abamectin
\end{abstract}

Palavras-chave: Lycopersicon esculentum, Bacillus thuringiensis, Neoleucinodes elegantalis, irrigação por aspersão, irrigação por gotejamento, tomate.

\section{ABSTRACT}

Effect of biofertilizer, and others biological and chemical products, in controlling the fruit small driller and in the production of staked tomato in two planting seasons and two irrigation systems.

The objective of this study was to evaluate the effects of a biofertilizer associated or not with biological and chemical products under different irrigation systems upon the yield of staked tomato and the occurrence of the "small fruit borer". The experiments were carried out at Itabaiana county, Sergipe State, Brazil, during the dry and wet seasons, on a randomized blocks design with 13 treatments and four replications. Each plot contained 48 plants, with two branches, spaced by $1.00 \times 0.50$ with one plant of two stems. The efficiency of the treatments varied according to the seasons and to the irrigation systems. Total and commercial yields in the wet season were respectively, 82 and $59 \%$ greater than the ones obtained in the dry season, also with a higher average fruit weight. Percentage of drilled fruits was significantly higher in the wet season than in the dry season. Best treatments for the dry season were: a) sprinkler irrigation: Bacillus thuringiensis variety Kurstaki (Btk) alone or in combination with clorfluazuron; deltametrina + clorfluazuron and biofertilizer + Btk; b) drip irrigation: Btk + clorfluazuron. For the wet season sowing the best treatments were: a) sprinkler irrigation: $B t k+$ clorfluazuron; biofertilizer + tefluazuron and clorfluazuron, and b) drip irrigation: biofertilizer + clorfluazuron and biofertilizer + abamectin.

Keywords: Lycopersicon esculentum, Bacillus thuringiensis, Neoleucinodes elegantalis, sprinkler irrigation, drips irrigation, tomato.

(Aceito para publicação em 01 de fevereiro de 2.001)

O tomate é uma das principais hortaliças cultivadas nas regiões produtoras do Estado de Sergipe. A região agreste de Itabaiana lidera a produção com uma área colhida de 116 hectares e rendimento médio de 13,60 t/ha (IBGE, 1996).

O tomate consumido nos sete Estados dentro dos Tabuleiros Costeiros provém em grande parte da importação, a exemplo de Sergipe, que atende apenas $21 \%$ de sua demanda interna. Ao lado dessa dependência por importação, existem grandes áreas produtoras e/ou em potenciais dentre os 305 municípios dos
Tabuleiros Costeiros. Entretanto, um dos principais entraves à cultura do tomate na região deve-se à ocorrência de pragas, especialmente da broca pequena do fruto (Neoleucinodes elegantalis). A mesma ocorre durante todos os meses do ano, sendo mais problemática na época das chuvas (maio a agosto) quando causa perdas de produção de até $90 \%$. Causa danos diretamente nos frutos, tornando-os imprestáveis ao consumo. $\mathrm{O}$ adulto deposita os ovos junto ao cálice ou sob as sépalas. As lagartas recémeclodidas levam em média 50 a 60 mi- nutos para penetrarem nos frutos ainda pequenos, nos quais deixam um orifício quase imperceptível, ocorrendo perfeita cicatrização. As lagartas desenvolvem-se no interior dos frutos, alimentando-se da polpa. No final de seu desenvolvimento, com aproximadamente 30 dias, abandonam o fruto fazendo um orifício grande e muitas vezes causando o apodrecimento. As lagartas de coloração rósea, de 11 a $13 \mathrm{~mm}$ de comprimento, empupam no solo próximo à planta por um período de 17 dias (Sandre Júnior et al., 1992). A infestação 
da broca varia com a época de plantio e com a cultivar utilizada. Em Sergipe constatou-se perdas que variaram de $66,21 \%$ para a cultivar Jumbo AG-592 a $92,75 \%$ para a cultivar Marglobe (Embrapa, 1994).

Os prejuízos causados por essa praga atingem até $90 \%$ dos frutos dependendo da época de plantio (Gallo et al., 1988), sendo os inseticidas fosforados não sistêmicos e carbamatos, aplicados quando os frutos ainda estão pequenos, apresentam um controle satisfatório. $\mathrm{O}$ controle químico é viável com o emprego de inseticidas piretróides e carbamatos, com pulverizações dirigidas para os frutos ainda novos, antes da penetração das lagartas (Filgueira, 1982). Vários autores avaliaram a eficiência de produtos químicos para o controle da broca pequena em diversas condições climáticas do Brasil. Raetano et al. (1993a), em Botucatu, constataram que a permetrina $(200 \mathrm{ml}$ p.c./100 L de água) foi o produto que apresentou maior eficiência, seguido pelo cartap (250g p.c./100 L de água) e pelo abamectin nas doses de 50, 75 e $100 \mathrm{ml}$ de p.c./100 L de água. Dentre os inseticidas piretróides avaliados por Raetano et al. (1993b), em Monte Mor (SP), a deltametrina, cipermetrina, permetrina e carbaryl foram igualmente eficientes, provocando um aumento significativo na produção. Em avaliações feitas por Bortoli \& Castellane (1988), os inseticidas lambdacyalothrin e permethrin propiciaram menores incidências de frutos brocados quando comparados com cartap e metamidophós. Em Pernambuco, Lyra Neto et al. (1991), constataram que a permetrina 500 foi o produto mais eficiente, tanto para o controle da broca pequena como para a traça. Nas condições de Lavras, de quatro produtos avaliados na época seca, destacaram-se o abamectin, permethrin e triflumuron, com eficiência superior a $80 \%$, e o clorfluazuron apresentou-se como o quarto produto menos eficiente (Reis \& Souza, 1995). Em Piracicaba, Moreno et al. (1995), constataram a eficiência da deltametrina e do tebufenozide na época seca. O mesmo não foi constatado em experimentos conduzidos em Camocin de São Félix (PE) onde o tra- tamento com deltametrina ficou em quarto lugar em relação à eficiência de controle desse inseto-praga (Lyra Neto et al. 1984).

Atualmente, além dos produtos organo-sintéticos, alguns de origem microbiológica, com eficiência sobre o controle de lagartas, vêm sendo estudados em relação à broca pequena do tomateiro. Souza \& Reis (1991) avaliaram Bacillus thuringiensis (200g p.c./ 100 L de água) e abamectin 18 CE (100 e $200 \mathrm{ml}$ p.c./100 L de água) aplicados em intervalos de sete dias. O tratamento mais eficiente foi o abamectin na dosagem de $200 \mathrm{ml}$, apresentando baixas porcentagens de frutos brocados. Verificaram também que a eficiência do abamectin não foi melhorada quando associado com o inseticida microbiano. Estes resultados contrariam os obtidos por Gravena (1989), que recomenda como melhor estratégia de controle da broca do tomateiro no MIP a aplicação de $B$. thuringiensis, semanalmente, nas doses de 0,016 a 0,032 kg i.a./ha. Por outro lado, Prando \& Silva Júnior (1990) constataram que, com aplicações semanais de $B$. thuringiensis (600g p.c./ha), houve controle de apenas $27,43 \%$ da broca pequena.

A associação de biofertilizantes com inseticidas químicos ou biológicos poderá ser uma alternativa viável no controle desta praga. O biofertilizante é um produto que tem ação inseticida e repelente não agressiva ao meio ambiente, atuando com maior eficiência como repelente de insetos adultos e alados, matando principalmente as formas jovens. É recomendado para o controle de pulgão, ácaros, mosca das frutas, lagartas, vaquinhas, percevejo e cochonilhas (Vairo, 1992).

A falta de cultivares resistentes, faz com que o controle químico seja o método mais utilizado. Mas, diante das grandes perdas de produção causadas pela broca, deve-se estudar também os fatores relacionados com o manejo da cultura, que favorecem a ocorrência desse inseto-praga.

No presente trabalho objetivou-se avaliar os efeitos da aplicação de biofertilizante e de produtos biológicos e químicos, em diferentes épocas de plantio sob diferentes sistemas de irri- gação, na produção e na incidência da broca pequena do tomateiro tutorado.

\section{MATERIAL E MÉTODOS}

Os experimentos foram conduzidos na área experimental da Emdagro/ Embrapa localizada no Perímetro Irrigado de Jacarecica, na região agreste de Itabaiana, à altitude de $180 \mathrm{~m}$ e em um planossolo eutrófico de textura arenoargilosa. O trabalho foi desenvolvido em três épocas de plantio: dezembro/95, junho/96 e maio/97, ou seja duas épocas de chuva (maio e junho) e um de seca (dezembro).

O delineamento experimental utilizado foi o de blocos ao acaso com quatro repetições e treze tratamentos: biofertilizante; biofertilizante + Bacillus thuringiensis subsp. kurstaki (Btk); biofertilizante + abamectin; biofertilizante + teflubenzuron; biofertilizante + deltametrina; biofertilizante + clorfluazuron; Btk; abamectin; Bacillus thuringiensis subsp. kurstaki e aizawai (Btka); deltametrina; clorfluazuron; deltametrina + clorfluazuron e Btk + clorfluazuron, avaliados sob irrigação por aspersão e por gotejamento. A parcela foi constituída por 48 plantas no espaçamento de $1,00 \times 0,50 \mathrm{~m}$ com uma planta por cova, conduzida com duas hastes, com tutoramento tipo cerca cruzada. Foram consideradas como úteis as 20 plantas centrais. Os produtos foram usados nas seguintes dosagens: Biofertilizante (50\%), Bacillus thuringiensis subsp. kurstaki $(6,72 \mathrm{~g}$ i.a./100 L de água); abamectin (0,9 ml i.a./100 L de água); teflubenzuron $(3,75 \mathrm{~g}$ i.a./100 L de água); deltametrina $(1,25 \mathrm{~g}$ i.a. $/ 100 \mathrm{~L}$ de água); clorfluazuron (5g i.a./100 L de água); Bacillus thuringiensis subsp. kurstaki e aizawai (5,7g i.a./100 L de água). O biofertilizante foi produzido por fermentação anaeróbica, em tonel plástico de 200 litros, onde foi colocado esterco fresco de bovino e água em partes iguais, deixando um espaço vazio de $15 \mathrm{~cm}$ entre a solução e a boca do tonel. Para escapamento do gás metano resultante da fermentação, foi colocada uma mangueira plástica tendo uma das extremidades em contato com o espaço vazio interno e a outra imersa em água 
contida em uma garrafa plástica transparente, por meio da qual foi acompanhado o processo de fermentação. Aos trinta dias, final da fermentação, o tonel foi aberto, coando-se o líquido e preparando uma solução a 50\% com água não clorada. Como o biofertilizante contém macro e micronutrientes em sua composição, que pode sofrer alterações com o decorrer do tempo após a abertura do tonel (Vairo, 1992), a porção líquida de cada tonel foi utilizada por um período de apenas oito dias.

As mudas foram produzidas em bandeja de isopor sob telado, com substrato formulado com pó de casca de coco (Nunes, 2000) e transplantadas com 25 dias após a semeadura. A adubação de plantio foi feita com esterco bovino na dosagem de 30 t/ha e com a fórmula 624-12 na dosagem de $150 \mathrm{~g} / \mathrm{m}$ de camalhão. O plantio foi feito em sistema de camalhões baixos, em torno de $10 \mathrm{~cm}$ de altura. Foram feitas duas amontoas, aos 30 e 60 dias. Para as adubações de cobertura utilizou-se o sulfato de amônio na dosagem correspondente a $40 \mathrm{~kg}$ de nitrogênio por hectare por ocasião de cada amontoa.

Os tratos culturais constaram de capina, amontoas, desbrotas e amarrios. Durante o desenvolvimento da cultura constatou-se a ocorrência da larva minadora (Liriomyza sp.) e pinta-preta (Alternaria solani), que foram controladas com cyromazine, iprodione e oxicloreto de cobre, respectivamente.

O início da colheita se deu aos 60 dias após o transplante e foram realizadas três colheitas na época seca e cinco colheitas na época de chuva. Foram avaliados todos os frutos colhidos na parcela útil e calculada a produção total, produção comercial e a percentagem da produção total perdida devido à incidência de broca. Os dados foram submetidos à análises de variância com posterior teste de Tukey ao nível de 5\% de probabilidade para comparações múltiplas entre médias de tratamentos. Também foram formulados contrastes entre médias de tratamentos, testados pelo teste t ao mesmo nível de significância.

Durante a fase experimental a temperatura variou de $18 \mathrm{a} 36^{\circ} \mathrm{C}$ no período de dezembro/95 a março/96; de $16^{\circ} \mathrm{C}$ a $31^{\circ} \mathrm{C}$ de junho a setembro/96 e de 17 a $31^{\circ} \mathrm{C}$ de maio a agosto/97. Registrou-se uma variação de precipitação mensal de $0 \mathrm{~mm}$ a $20,3 \mathrm{~mm} ; 33,3 \mathrm{~mm}$ a $332,2 \mathrm{~mm}$ e de $3,8 \mathrm{~mm}$ a $284,2 \mathrm{~mm}$ nos respectivos períodos acima citados.

\section{RESULTADOS E DISCUSSÃO}

As análises conjuntas dos experimentos, segundo metodologia proposta por Gomes (1985), realizadas dentro de cada época (seca e chuva), dentro de cada sistema de irrigação (aspersão e gotejamento), ou ainda considerando-se todos os fatores estudados (época, sistema de irrigação e biofertilizante) numa análise mais geral, evidenciaram interações significativas entre estes três fatores, em todos os níveis, não sendo possível, portanto, a indicação do biofertilizante sem considerar a época de plantio e o sistema de irrigação utilizado.

Entretanto, apesar das interações observadas entre os efeitos de época $\mathrm{x}$ biofertilizante e época x sistema de irrigação, o efeito principal da época de plantio sobrepujou os efeitos secundários das interações, podendo-se concluir que, de um modo geral, na época de chuva obteve-se maiores produções total (50,61 t/ha) e comercial (37,34 t/ha), superando as produções obtidas na época seca em $82 \%$ e $59 \%$, respectivamente, e um maior peso médio de frutos (90,41 g e 70,80 g nas épocas de chuva e seca respectivamente). Também na época de chuva a percentagem de frutos brocados $(23,25 \%)$ foi significativamente superior àquela obtida na época seca $(5,89 \%)$.

Conclusões semelhantes podem ser tomadas com relação ao efeito do sistema de irrigação, em que o gotejamento proporcionou maiores produções total e comercial e maior peso médio dos frutos $(43,85 \mathrm{t} / \mathrm{ha}, 34,66 \mathrm{t} / \mathrm{ha}$ e $84,28 \mathrm{~g}$, respectivamente), superando em $27 \%$; $32 \%$ e 9,5\% aqueles obtidos na irrigação por aspersão. Neste sistema de irrigação também se observou uma menor percentagem de frutos brocados $(13,68 \%)$ do que com o uso da irrigação por aspersão $(15,45 \%)$. Esses resultados indicam que o tomateiro tutorado é uma planta mais adaptada à irrigação por gotejamento, a qual evita a lavagem dos produtos aplicados na parte aérea e cria um microclima desfavorável à infestação da broca pequena do fruto.

Os resultados com relação aos produtos utilizados serão discutidos dentro de cada situação, de acordo com as análises de cada experimento, em particular. Houve efeito significativo entre os tratamentos dentro de cada época de plantio e de cada sistema de irrigação utilizado, para produção total, comercial e de frutos brocados.

No plantio da época seca com o uso da irrigação por aspersão (Tabela 1), houve destaque do tratamento com Btk seguido pelos tratamentos deltametrina + clorfluazuron e Btk + clorfluazuron que não diferiram estatisticamente, tanto para produção total como para a produção comercial. Na produção comercial, a aplicação de biofertilizante $+B t k$, não diferiu estatisticamente de $B t k$; deltametrina + clorfluazuron $e$ Btk + clorfluazuron. Estes tratamentos apresentaram também menores perdas de frutos brocados, destacando-se a aplicação de biofertilizante $+B t k$. A eficiência deste Bacillus foi comprovada também por Gravena (1989) no controle de Neoleucinodes elegantalis no MIP. Constatou-se que o efeito do clorfluazuron tanto em relação à produção total e comercial quanto à percentagem de frutos brocados, aumentou significativamente quando associado com deltametrina ou Btk. A aplicação de deltametrina, isoladamente, foi o tratamento que apresentou maior percentagem de frutos brocados, resultado que discorda daqueles encontrados por Raetano et al. (1993b) e da recomendação de Filgueira (1982), porém foi um dos tratamentos mais eficiente quando em combinação com o clorfluazuron.

O teste t para contrastes entre médias de tratamentos, ao nível de 5\% de significância, confirmou os resultados do teste de Tukey, apresentados na tabela 1 . Pelo teste $t$, a utilização da combinação biofertilizante + deltametrina resultou em maior produção comercial e menor percentagem de frutos brocados que a aplicação de deltametrina, isoladamente $(t=4,55$ e $t=4,12$, respectivamente). A combinação deltametrina + clorfluazuron também foi mais eficiente que a deltametrina, tanto na produção comercial $(\mathrm{t}=11,42)$ quanto na redução de fru- 
Tabela 1. Produção e perdas causadas pela broca pequena do fruto do tomateiro com plantio em época seca e sob irrigação por aspersão, em função de tratamentos com biofertilizante e inseticidas biológicos e químicos. Aracaju (SE), Embrapa Tabuleiros Costeiros, 1995 - 1997.

\begin{tabular}{|c|c|c|c|c|}
\hline Tratamento & $\begin{array}{l}\text { Produção total } \\
\text { (t/ha) }\end{array}$ & $\begin{array}{l}\text { Produção comercial } \\
\text { (t/ha) }\end{array}$ & Perda & $\begin{array}{l}\text { por broca } \\
\text { (\%) }\end{array}$ \\
\hline Biofertilizante & 24,34 & 20,37 & 7,50 & bcd \\
\hline B. thuringiensis subsp. kurstaki (Btk) & $33,56 \mathrm{a}$ & $28,95 \mathrm{a}$ & 4,95 & ef \\
\hline Biofertilizante + Btk. & 29,97 bc & $26,32 \mathrm{abc}$ & 4,65 & $f$ \\
\hline Clorfluazuron & 29,34 bc & 24,00 bcde & 6,00 & cdef \\
\hline Biofertilizante + clorfluazuron & $28,34 \mathrm{~cd}$ & 23,90 bcd & 6,74 & bcde \\
\hline Abamectin & 25,52 & 21,07 & 6,83 & bcde \\
\hline Biofertilizante + abamectin & 28,52 & 22,55 & 6,57 & bcdef \\
\hline Deltametrina & 22,65 & 16,62 & 10,74 & \\
\hline Biofertilizante + deltametrina & 24,88 & 20,48 & 8,50 & $\mathrm{~b}$ \\
\hline Biofertilizante + teflubenzuron & 23,23 & 19,34 & 7,95 & bc \\
\hline Btk+ clorfluazuron & $31,54 \mathrm{abc}$ & $27,09 a b$ & 5,53 & def \\
\hline Deltametrina + clorfluazuron & $32,63 a b$ & $26,31 \mathrm{abc}$ & 5,14 & ef \\
\hline $\begin{array}{l}\text { B. thuringiensis subsp. kurstaki e } \\
\text { aizawai (Btka) }\end{array}$ & $28,84 \mathrm{~cd}$ & $24,58 \mathrm{bcd}$ & 5,28 & ef \\
\hline C. V. & 3,98 & 4,48 & 10,00 & \\
\hline Média Geral & 27,95 & 23,20 & 6,64 & \\
\hline D. M. S. & 3,33 & 3,11 & 1,99 & \\
\hline
\end{tabular}

tos brocados $(\mathrm{t}=10,31)$. A combinação Btk + clorfluazuron superou, em produção comercial, o efeito do clorfluazuron aplicado isoladamente $(\mathrm{t}=3,65)$.

Os dados de produção obtidos no plantio na época de chuva (maio/junho) com um complemento de irrigação por aspersão (Tabela 2), mostraram que os tratamentos com Btk + clorfluazuron e com biofertilizante + teflubenzuron apresentaram produções totais estatisticamente superiores aos demais. Em produção comercial, destacaram-se estes tratamentos além daqueles em que foi usado o clorfluazuron isoladamente. $\mathrm{O}$ resultado obtido com o uso do clorfluazuron, em relação à ocorrência de broca, discorda daquele obtido por Reis \& Souza (1995) em Lavras, em que esse produto foi o menos eficiente no controle da broca pequena do tomateiro. Tal fato, pode estar relacionado com as condições climáticas de cada local de aplicação. O tratamento com biofertilizante + teflubenzuron além de apresentar maior produção comercial foi um dos mais eficientes no controle da broca pequena do fruto. $\mathrm{O}$ tratamento com abamectin está entre aqueles que apresentaram menores produções comerciais e maior incidência de broca, cujo efeito foi significativamente melhorado quando associado com o biofertilizante. $\mathrm{O}$ resultado obtido com a aplicação isolada de abamectin foi semelhante àquele citado por Raetano et al. (1993a) e contrário ao obtido por Reis \& Souza (1995). As melhores produções e controle da broca pequena do fruto devido à associação do biofertilizante aos inseticidas teflubenzuron e abamectin, estão relacionados com o efeito nutricional e inseticida do biofertilizante, como referenciado por Vairo (1992). O teste t para contrastes entre médias de produção comercial mostrou haver superioridade das combinações biofertilizante + abamectin e biofertilizante + Btk sobre o abamectin e o Btk, utilizados isoladamente $(t=10,18$ e $t=3,65$ respectivamente), confirmando o efeito positivo do biofertilizante nesta situação. Também a produção comercial média obtida na combinação Btk + clorfluazuron foi significativamente superior às obtidas nestes dois produtos isolados $(\mathrm{t}=13,37 \mathrm{e}$ $t=3,17$ respectivamente). Estes resultados confirmam, em parte, aqueles mostrados na tabela 2 .

Com o uso da irrigação por gotejamento, na época seca (Tabela 3) o tratamento com Btk + clorfluazuron apresentou maior produção total e comercial que todos os demais tratamentos e uma das menores perdas de produção devido à ocorrência de broca $(4,30 \%)$. Nestas condições de cultivo sobressaiu, em segundo lugar, o tratamento com clorfluazuron, em produção total e comercial, apresentando também pequena perda de frutos brocados $(4,48 \%)$. Em relação à produção comercial, o uso de Btk, biofertilizante + clorfluazuron e biofertilizante + teflubenzuron não diferiram estatisticamente entre si, fazendo parte dos melhores tratamentos, porém inferiores ao tratamento de Btk + clorfluazuron. O teste $t$ não evidenciou contrastes significantes entre os produtos usados isoladamente ou em combinação com o biofertilizante.

Nessa época de plantio (época seca), com o uso da irrigação por aspersão (Tabela 1), a média geral da produção comercial foi de 23,20 t/ha com uma perda de 6,64\% devido à ocorrência da broca pequena do fruto. Usando a irrigação por gotejamento (Tabela 3 ) obteve-se uma produção comercial média de 23,74 t/ha e uma perda de $5,13 \%$ de frutos brocados. 
Tabela 2. Produção e perdas causadas pela broca pequena do fruto do tomateiro com plantio em época de chuva e sob irrigação por aspersão, em função de tratamentos com biofertilizante e inseticidas biológicos e químicos. Aracaju (SE), Embrapa Tabuleiros Costeiros, $1995-1997$.

\begin{tabular}{|c|c|c|c|c|c|c|}
\hline \multirow{2}{*}{$\begin{array}{l}\text { Tratamento } \\
\text { Biofertilizante }\end{array}$} & \multicolumn{2}{|c|}{$\begin{array}{l}\text { Produção total } \\
\text { (t/ha) }\end{array}$} & \multicolumn{2}{|c|}{$\begin{array}{l}\text { Produção comercial } \\
\text { (t/ha) }\end{array}$} & \multicolumn{2}{|c|}{$\begin{array}{l}\text { Perda por broca } \\
\text { (\%) }\end{array}$} \\
\hline & 33,75 & $\mathrm{~g}$ & 22,09 & e & 22,88 & def \\
\hline B. thuringiensis subsp. kurstaki (Btk) & 37,50 & ef & 25,81 & d & 22,81 & def \\
\hline Biofertilizante + Btk & 41,29 & $\mathrm{~cd}$ & 28,80 & bc & 24,92 & bcd \\
\hline Clorfluazuron & 43,82 & bc & 34,00 & & 21,27 & ef \\
\hline Biofertilizante + clorfluazuron & 40,19 & de & 27,12 & cd & 24,33 & cde \\
\hline Abamectin & 35,48 & fg & 21,09 & e & $33,66 a$ & \\
\hline Biofertilizante + abamectin & 39,91 & de & 29,16 & bc & 22,33 & def \\
\hline Deltametrina & 41,32 & cd & 28,98 & bc & 26,88 & bc \\
\hline Biofertilizante + deltametrina & 41,66 & cd & 29,41 & bc & 26,50 & b \\
\hline Biofertilizante + teflubenzuron & $46,27 a$ & & 36,61 & & 19,81 & $f$ \\
\hline Btk + clorfluazuron & $49,04 a$ & & 36,51 & & 22,16 & def \\
\hline Deltametrina + clorfluazuron & 42,08 & cd & 28,41 & bcd & 28,00 & b \\
\hline $\begin{array}{l}\text { B. thuringiensis subsp. Kurstaki e } \\
\text { aizawai (Btka) }\end{array}$ & 42,71 & $\mathrm{~cd}$ & 30,33 & b & 19,92 & $f$ \\
\hline C. V. & 2,83 & & 3,34 & & 4,60 & \\
\hline Média Geral & 41,16 & & 29,10 & & 24,27 & \\
\hline D. M. S. & 3,48 & & 2,90 & & 3,34 & \\
\hline
\end{tabular}

Tabela 3. Produção e perdas causadas pela broca pequena do fruto do tomateiro com plantio na época seca e sob irrigação por gotejamento, em função de tratamentos com biofertilizante e inseticidas biológicos e químicos. Aracaju (SE), Embrapa Tabuleiros Costeiros, $1995-$ 1997.

\begin{tabular}{|c|c|c|c|}
\hline Tratamento & $\begin{array}{l}\text { Produção total } \\
\text { (t/ha) }\end{array}$ & $\begin{array}{l}\text { Produção comercial } \\
\text { (t/ha) }\end{array}$ & $\begin{array}{l}\text { Perda por broca } \\
\text { (\%) }\end{array}$ \\
\hline Biofertilizante & $25,46 \quad$ def & $19,61 \quad \mathrm{fg}$ & $6,91 \mathbf{a}$ \\
\hline B. thuringiensis subsp. kurstaki (Btk) & 28,53 & 24,95 bc & $4,52 \mathrm{~cd}$ \\
\hline Biofertilizante + Btk & 25,48 & 22,04 & 4,26 \\
\hline Clorfluazuron & 31,37 b & 28,01 b & 4,48 \\
\hline Biofertilizante + clorfluazuron & 28,13 & 25,11 bc & 5,37 abcd \\
\hline Abamectin & 29,08 & 23,69 & $6,57 \mathrm{ab}$ \\
\hline Biofertilizante + abamectin & 24,59 & 20,33 & 4,92 bcd \\
\hline Deltametrina & 28,98 bc & 24,41 & $4,34 \mathrm{~cd}$ \\
\hline Biofertilizante + deltametrina & 22,51 & 17,68 & $5,82 \mathrm{abc}$ \\
\hline Biofertilizante + teflubenzuron & 27,29 & 25,09 bc & $4,13 \quad d$ \\
\hline Btk + clorfluazuron & 35,89 a & 32,92 a & $4,30 \mathrm{~cd}$ \\
\hline Deltametrina + clorfluazuron & 25,29 & 21,68 & $6,37 \mathrm{ab}$ \\
\hline $\begin{array}{l}\text { B. thuringiensis subsp. kurstaki e } \\
\text { aizawai (Btka) }\end{array}$ & 26,53 & 23,15 & 4,68 \\
\hline C. V. & 4,13 & 4,51 & 10,86 \\
\hline Média Geral & 27,72 & 23,79 & 5,17 \\
\hline D. M. S. & 3,41 & 3,20 & 1,66 \\
\hline
\end{tabular}

Na época de chuva e com o complemento da irrigação por gotejamento (Tabela 4), as maiores produções totais e comerciais e as menores perdas de produção devido à ocorrência da broca foram obtidas com aplicação de biofertilizante + abamectin e de biofertilizante + clorfluazuron, cujos resultados não diferiram estatisticamen- 
Tabela 4. Produção e perdas causadas pela broca pequena do fruto do tomateiro com plantio na época das chuvas e sob irrigação por gotejamento, em função de tratamentos com biofertilizante e inseticidas biológicos e químicos. Aracaju (SE), Embrapa Tabuleiros Costeiros, $1995-1997$.

\begin{tabular}{|c|c|c|c|c|c|}
\hline \multirow{2}{*}{$\begin{array}{l}\text { Tratamento } \\
\text { Biofertilizante }\end{array}$} & \multicolumn{2}{|c|}{$\begin{array}{l}\text { Produção total } \\
\text { (t/ha) }\end{array}$} & \multicolumn{2}{|c|}{$\begin{array}{l}\text { Produção comercial } \\
\text { (t/ha) }\end{array}$} & $\begin{array}{c}\text { Perda por broca } \\
(\%)\end{array}$ \\
\hline & 58,65 & e & 44,97 & cde & 21,56 bcd \\
\hline B. thuringiensis subsp. kurstaki (Btk) & 59,45 & de & 43,87 & cde & $23,23 a b c$ \\
\hline Biofertilizante + Btk & 57,06 & ef & 43,51 & de & 21,48 \\
\hline Clorfluazuron & 59,64 & cde & 45,72 & cd & 21,90 bcd \\
\hline Biofertilizante + clorfluazuron & \multicolumn{2}{|c|}{$65,36 \mathrm{ab}$} & \multicolumn{2}{|c|}{52,01 a } & 20,11 \\
\hline Abamectin & 53,99 & $\mathrm{fg}$ & 41,35 & ef & 21,59 \\
\hline Biofertilizante + abamectin & \multicolumn{2}{|c|}{65,89 a } & \multicolumn{2}{|c|}{$51,35 a b$} & 19,79 \\
\hline Deltametrina & 60,82 & bcde & 43,44 & de & 25,95 a \\
\hline Biofertilizante + deltametrina & 52,10 & g & 37,83 & $\mathrm{f}$ & $24,93 a b$ \\
\hline Biofertilizante + teflubenzuron & \multicolumn{2}{|c|}{$64,20 \mathrm{abc}$} & \multicolumn{2}{|c|}{$48,19 a b c$} & 22,73 abcd \\
\hline Btk + clorfluazuron & 59,94 & cde & 46,21 & cd & 21,83 bcd \\
\hline Deltametrina + clorfluazuron & 60,61 & cde & 46,49 & cd & $21,00 \quad c d$ \\
\hline $\begin{array}{l}\text { B. thuringiensis subsp. kurstaki e } \\
\text { aizawai (Btka) }\end{array}$ & \multicolumn{2}{|c|}{63,28 abcd } & \multicolumn{2}{|l|}{47,55} & 22,95 abcd \\
\hline C. V. & \multicolumn{2}{|l|}{2,58} & \multicolumn{2}{|l|}{3,25} & 5,09 \\
\hline Média Geral & \multicolumn{2}{|l|}{60,08} & \multicolumn{2}{|l|}{45,58} & 22,23 \\
\hline D. M. S. & \multicolumn{2}{|l|}{4,63} & \multicolumn{2}{|l|}{4,43} & 3,38 \\
\hline
\end{tabular}

te entre si. Também aqui foram constatadas diferenças significativas, tanto pelo teste de Tukey quanto pelo teste t, entre os tratamentos biofertilizante + abamectin e abamectin, com relação à produção comercial e percentagem de frutos brocados $(t=8,26 \mathrm{e} t=3,25$, respectivamente), indicando um melhor efeito da combinação sobre o produto isolado no aumento da produtividade e redução da broca, à semelhança do observado no mesmo período, com a irrigação por aspersão (Tabela 2). Somente nessa época e com a irrigação por gotejamento, foram evidenciadas médias de produção total e comercial significativamente superiores do tratamento biofertilizante + clorfluazuron, quando comparado ao clorfluazuron isolado $(\mathrm{t}=5,19)$.

Constatou-se, pelas médias gerais, maior ocorrência de broca pequena do fruto nos plantios feitos na época de chuva (Tabelas 2 e 4), onde a perda média de produção foi $17,63 \%$, superior ao do plantio realizado na época seca (Tabelas 1 e 3 ). A produção total, produção comercial e o peso médio de fruto obtidos nos cultivos feitos na época de chuva, foram superiores em $47 \%$, $25 \%$ e $28 \%$, respectivamente, em relação à época seca.
O fato da maior ocorrência de broca ter sido observado na época de chuva, pode estar relacionado com a maior lavagem dos produtos aplicados e com a maior infestação desse inseto-praga favorecida pelas condições climáticas nesse período. Por outro lado as maiores produções na época de chuva podem ser devido à ocorrência de temperaturas mais amenas, principalmente à noite, que são favoráveis ao vingamento de flores e formação de frutos.

No presente trabalho observou-se que as plantas que receberam a aplicação de biofertilizante apresentaram maior vigor e coloração verde mais intensa em relação aos demais tratamentos.

Diante dos resultados alcançados nas condições em que foram desenvolvidos os experimentos, conclui-se que o efeito dos tratamentos variou com a época de plantio e com o sistema de irrigação utilizado. Os melhores tratamentos, em ordem decrescente, foram: a) Época seca com a irrigação por aspersão: Btk; $B t k+$ clorfluazuron; deltametrina + clorfluazuron; biofertilizante $+B t k$; b) Época seca com irrigação por gotejamento: Btk + clorfluazuron.; c) Época de chuva com a irrigação por aspersão: Btk + clorfluazuron; biofertilizante + teflubenzuron e clorfluazuron; d) Época de chuva com a irrigação por gotejamento: biofertilizante + clorfluazuron e biofertilizante + abamectin. $\mathrm{O}$ biofertilizante por ser um adubo foliar orgânico, tem o efeito de nutrir a planta influenciando no seu desenvolvimento, e consequentemente na produção. Estes efeitos somados ao efeito inseticida de alguns produtos, resultam em melhores produções e controle da broca pequena do fruto do tomateiro.

\section{AGRADECIMENTOS}

Agradecemos ao Técnico Agrícola da EMDAGRO Waltênis Braga Silva e ao Técnico Agrícola da Embrapa Tabuleiros Costeiros, Arnaldo Santos Rodrigues pelo apoio técnico e dedicação na condução dos experimentos e coleta dos dados em campo.

\section{LITERATURA CITADA}

BORTOLI, S.A.; CASTELLANE, P.D. Controle químico da traça do tomateiro e de brocas dos frutos em tomateiro 'Kazue', 1988. Horticultura Brasileira, Brasília, v. 6, n. 2, p. 27-28, nov. 1988 . 
Efeitos da aplicação de biofertilizante e outros produtos químicos e biológicos, no controle da broca pequena do fruto e na produção do tomateiro tutorado em duas épocas de cultivo e dois sistemas de irrigação.

EMBRAPA. Centro de Pesquisa Agropecuária dos Tabuleiros Costeiros (Aracaju, SE). Relatório Técnico Anual do Centro de Pesquisa Agropecuária dos Tabuleiros Costeiros. Aracaju, 1994. 105 p.

FILGUEIRA, F.A.R. Manual de Olericultura. 2 ed. São Paulo: Agronômica Ceres, 1982. 286 p. v. 2.

GALLO, D.; NAKANO, 0.; SILVEIRA NETO, S.; CARVALHO, R.P.L.; BATISTA, G.C., BERTI FILHO, E.; PARRA, J.R.P.; ZUCHI, R.A.; ALVES, S.B. Manual de entomologia agrícola, 2 ed., São Paulo, Agronômica Ceres, 1988. 649 p.

GOMES, F.P. Curso de estatística experimental. 11 ed. revista e ampl. Piracicaba: ESALQ, 1985. $466 \mathrm{p}$.

GRAVENA, S. Manejo integrado de pragas do tomateiro. In: ENCOTRO NACIONAL DE PRODUÇÃO E ABASTECIMENTO DE TOMATE, 1, 1989, Viçosa, Anais... Viçosa: EMATER - MG, 1989. p. 36-51.

IBGE, RJ. Produção Agrícola Municipal. Rio de Janeiro: IBGE, 1996. Disponível: http:// www.sidra.ibge.gov.br. consultado em 16de maio de 2000.

LYRA NETO, A.M.C.; WANDERLEY, L.J.G.; MELO, P.C.T. Controle químico de Neoleucinodes elegantalis (GUENÉE, 1854) e Scrobipalpula absoluta (Meyrik, 1917)) (Lepidoptera: Gelechhiidal) no tomateiro em Pernambuco. Anais da Sociedade Entomológica do Brasil, Porto alegre, v. 20, n. 2, p. 353-358, 1991.
LYRA NETO, A.M.C.; WANDERLEY, L.J.G.; MELO, P.C.T.; SANTOS, V.F. Controle de pragas do tomateiro (Neoleucinodes elegantalis) e (Scrobipalpula absoluta) em Pernambuco. IN: CONGRESSO BRASILEIRO DE OLERICULTURA, 24, 1984, Jaboticabal. Resumos. Jaboticabal: SOB, 1984. p. 145.

MORENO, P.R.; NAKANO, O.; ANDRADE, F.M.E.; DODO, S. Controle da broca pequena do tomateiro Neoleucinodes elegantalis (GUENÉE, 1854) (Lepidoptera - Pyralidae) com um novo inseticida fisiológico denominado Tebufenozide. IN: CONGRESSSO BRASILEIRO DE ENTOMOLOGIA, 15,1995, Caxambu. Resumos Caxambu: SEB, 1995, p. 512.

NUNES, M.U.C. Produção de mudas de hortaliças com o uso da plasticultura e do pó de coco. Aracaju: Embrapa - CPATC, 2000. 29 p. (Embrapa - CPATC. Circular Técnica, 13).

PRANDO, H.F.; SILVA Jr., A.A. Eficácia de seis inseticidas no controle de Neoleucinodes elegantalis (GUENÉE, 1854) (Lepidoptera Pyralidae) em tomate. Anais da Sociedade Entomológica do Brasil., Itabuna, v. 19, n. 1, p. 59-63, 1990.

RAETANO, C.G.; GUASSU, C.M.O.; CROCOMO, W.B.; WILKEN, C.F. Avaliação da eficiência do abamectin no controle da broca pequena do tomateiro Neoleucinodes elegantalis (GUENÉE, 1854) (Lepidoptera Pyralidae) em tomate estaqueado. Científica, São Paulo, v. 22, n. 2, p. 221-229, 1993 a.
RAETANO, C.G.; GUASSU, C.M.O.; CROCOMO, W.B. Eficiência de inseticidas piretróides no controle da broca pequena do tomateiro - Neoleucinodes elegantalis (GUENÉE, 1854) (Lepidoptera - Pyralidae), em tomate estaqueado. Científica, São Paulo, v. 21 , n. 1, p. 197-202,1993b.

REIS, P.R.; SOUZA, J.C. Controle da broca pequena, Neoleucinodes elegantalis, (GUENÉE, 1854) (Lepidoptera - Pyralidae), com inseticidas fisiológicos, em tomateiro estaqueado. In: CONGRESSO BRASILEIRO DE ENTOMOLOGIA, 15, 1995, Caxambu. Resumos ... Caxambu: SEB, 1995, p. 443.

SANDRE Jr., P.; SILVA, A.L.; ALCANTARA, V.E.D.; FARIAS, T.A. Ensaio para o controle químico da broca pequena Neoleucinodes elegantalis (GUENÉE, 1854) (Lepidoptera Pyralidae) do tomateiro. Anais da Escola de Agronomia e Veterinária , v. 21/22, n. 1, p. 127-131, 1991/1992.

SOUZA, J.C., REIS, P.R. Eficiência do inseticida Vertimec (Abamectin) 18CE no controle da broca pequena do tomate Neoleucinodes elegantalis (GUENÉE, 1854) (Lepidoptera Pyralidae), em tomateiro estaqueado. In: CONGRESSO BRASILEIRO DE ENTOMOLOGIA, 13, 1991, Recife. Resumos ... Recife: SEB, 1991. v. 2, p. 453.

VAIRO, S.A.C. Biofertilizante líquido: o defensivo agrícola da natureza. Niterói, EMATER Rio, Agropecuária Fluminense, Rio de Janeiro, n. 8, 16 p. 1992. 